\title{
LUNG FUNCTION STUDIES. I. THE RATE OF INCREASE OF ARTERIAL OXYGEN SATURATION DURING THE INHALATION OF 100 PER CENT $\mathrm{O}_{2}{ }^{1}$
}

\author{
BY WARD S. FOWLER ${ }^{2}$ aND JULIUS H. COMROE, JR. \\ (From the Department of Physiology and Pharmacology, Graduate School of Medicine, \\ University of Pennsylvania, Philadelphia)
}

(Received for publication December 1, 1947)

It has been noted $(1,2,3)$ that the rate at which arterial oxygen saturation (measured by the oximeter) rises during the inhalation of $100 \%$ oxygen is considerably slower than expected, if complete saturation of hemoglobin occurs at a $\mathrm{pO}_{2}$ of $159 \mathrm{~mm} . \mathrm{Hg}$ at $37^{\circ} \mathrm{C}$., as is commonly believed (4, 5 ). We have been impressed by the finding that otherwise normal men, made anoxemic by the inhalation of $10 \% \mathrm{O}_{2}$, attain $100 \%$ oxygen saturation of arterial hemoglobin practically as quickly as do normal men previously breathing room air, if both groups be given $100 \% \mathrm{O}_{2}$ to breathe. In both groups the rise in saturation from either $70 \%$ or $95 \%$ is very rapid until $98-99 \%$ saturation is reached but the attainment of the last $1-2 \%$ in all subjects is a much slower process.

The studies to be reported here represent an attempt to analyze the possible causes of the slow rise in arterial oxygen saturation that occurs in the extreme upper portion of the dissociation curve. Several explanations may be advanced for this phenomenon: $(a)$ delayed ventilation may occur in some alveoli through which blood is circulating (2); (b) alveolar $\mathrm{pO}_{2}$ may not be raised promptly enough even in wellventilated alveoli; (c) the arterial $\mathrm{pO}_{2}$ may not be in equilibrium with the alveolar $\mathrm{pO}_{2}$ during periods involving rapid and large changes in alveolar $\mathrm{pO}_{2}(1)$; $(d)$ venous-arterial shunts, bypassing the pulmonary circulation, may exist; $(e)$ incomplete mixing of arterialized blood may occur; (f) the oximeter may not be analyzing pure arterial blood but blood from which some oxygen has

\footnotetext{
1 The work described in this paper was done under contract between the Medical Division, Chemical Corps, U. S. Army, and the University of Pennsylvania. Under the terms of this contract, the Chemical Corps neither restricts nor is responsible for the opinions or conclusions of the authors.

2 Research Fellow of the American College of Physicians.
}

been extracted by the metabolism of ear tissues; or $(g)$ hemoglobin may require exposure to oxygen tensions considerably in excess of that in room air $(159 \mathrm{~mm} . \mathrm{Hg})$ to achieve complete saturation.

The simultaneous use of the nitrogen analyzer and oximeter to record continuously the nitrogen content of respired air and oxygen saturation of arterial blood, respectively, has yielded data which permit us to analyze some of these factors more closely.

\section{METHODS}

1. Forty-five healthy white male subjects (medical students and physicians) between the ages of 19 and 31 were studied.

2. Arterial oxygen saturation was measured with the automatically compensated oximeter (6). Oximeter saturation changes were observed visually and recorded by $0.25 \%$ intervals; this was permitted by a narrow galvanometer beam. The instrumental lag to complete deflection is about six seconds. After the start of $\mathrm{O}_{2}$ inhalation, saturation readings were made at intervals of ten seconds for two minutes, and at 30-second intervals thereafter until five minutes had elapsed. Readings taken at intervals of five seconds for the first 90 seconds on 17 subjects showed that no significantly different rate of increase was obtained by reading at the shorter time intervals. Ear thickness readings were checked at 130 seconds and five minutes to note any change in vasodilation. In some subjects, oximeter saturation readings were made at 30 -second intervals for two minutes after the subject resumed breathing room air."

\footnotetext{
${ }^{3}$ Calibration studies of the oximeter readings against direct arterial blood analyses have estimated the oximeter error at not over $5 \%$. However, the accuracy of our measurements cannot be assessed by saying that the oximeter is accurate only within $5 \%$. First, it is pointed out by Hemingway and Taylor (7) that, in their method of testing, agreement of better than $5 \%$ is not possible, due to certain random errors inherent in the method of testing which would account for discrepancies of $2-5 \%$ even if the oximeter gave the correct instantaneous saturation value. Secondly, for assessing the significance of small changes, we feel that these changes are best compared with the variability observed during the control periods before and after the test procedure.
} 
3. Analysis of the respired air was made continuously with a nitrogen meter $(8,9)$. This instrument continuously samples, analyzes and records the nitrogen content of constant composition samples with an accuracy from day to day of $\pm 2 \% \mathrm{~N}_{2}$ relative to Haldane analyses. This is an overall accuracy summing errors in sampling methods, measurement of records and setting the instrument. However, the accuracy for changes in gas composition over short time periods is probably better. The instrumental delay between the time the sample enters the analyzer and the initial change in the record is about 0.04 second. To a stepwise change in composition, the instrument requires approximately 0.07 second to record $95 \%$ of the final value.

The sampling needle was placed in the middle of the mouthpiece lumen 1-2 cm. external to the subject's lips. Continuous analysis was made of the respired gases for the first two minutes after inhalation of $\mathrm{O}_{2}$, and one to two breaths were analyzed after five minutes on $\mathrm{O}_{2}$. After the subject resumed breathing room air following the five-minute period on $\mathrm{O}_{2}$, continuous analysis of the respired gas was made for the first two minutes.

4. Breathing apparatus. A rubber mouthpiece and nose clip were used. Subjects breathed through a four-way valve of $2 \mathrm{~cm}$. internal diameter. Room air was breathed through one orifice, a dead space of $40 \mathrm{cc}$. being thus added. With this orifice closed, the subject inspired 99.6\% oxygen from a high pressure supply tank through a demand regulator, and exhaled through a Sadd valve to room air. When the subject breathed oxygen, the apparatus dead space was $60 \mathrm{cc}$. When gases other than $\mathrm{O}_{2}$ were breathed, these were stored in high pressure tanks and supplied to the subject by a similar demand regulator connected to the mouthpiece via a three-way stopcock.

5. Procedure. Subjects were not in basal condition, but sat quietly in a chair for ten to 15 minutes before inhaling oxygen. During this time the oximeter ear unit was placed on the ear. After "ear thickness" readings became stable, the subject breathed room air through the mouthpiece and the saturation reading was arbitrarily set at $95-96 \%$. If breathing was quiet and regular, this reading was very stable. After the saturation reading was made with the subject breathing room air, the recording camera of the nitrogen meter was started, the room-air orifice in the four-way valve was closed during an expiration, and the start of the following inspiration of oxygen was timed with a stop watch. The hissing noise of the demand regulator served as a convenient signal of the start of inspiration. Thereafter oximeter and nitrogen analyzer readings were made as stated above. Throughout the procedure the subject breathed quietly in a sitting position.

\section{RESULTS}

1. Arterial oxygen saturation increase. Figure 1 shows graphically the manner in which arterial oxygen saturation increases. After an average delay of 7.1 seconds following the start of the first inhalation of oxygen, saturation begins to increase. This delay represents the interval between the times that $\mathrm{O}_{2}$ enters the mouth and more fully oxygenated blood reaches the ear. As such it measures the time required for movement of $\mathrm{O}_{2}$ to the alveoli, for diffusion of $\mathrm{O}_{2}$ across the alveolar membrane, and the circulation time from lung to ear capillaries. Data obtained in this study indicate that inhalation of $\mathrm{O}_{2}$ is a more satisfactory and less hazardous method for estimating "lung to ear" (actually "mouth to lung to ear") circulation time than is inhalation of a deep breath of $\mathrm{N}_{2}$, a method used by Wexler and Whittenberger (10).

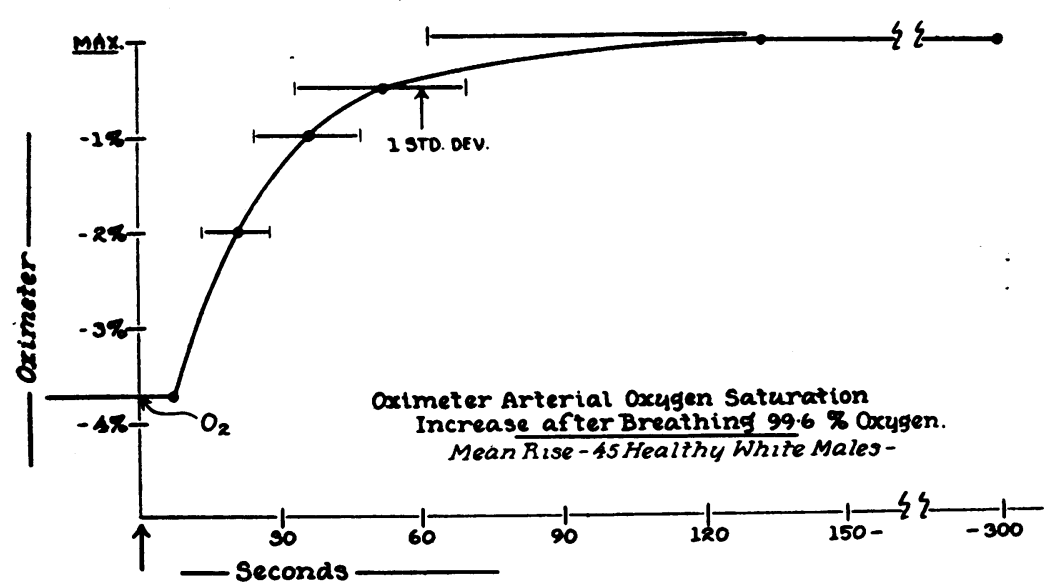

Fig. 1. Rate of Increase of Arterial Oxygen Saturation (Oximeter) During the Change from Inhalation of Air to $99.6 \%$ Oxygen 


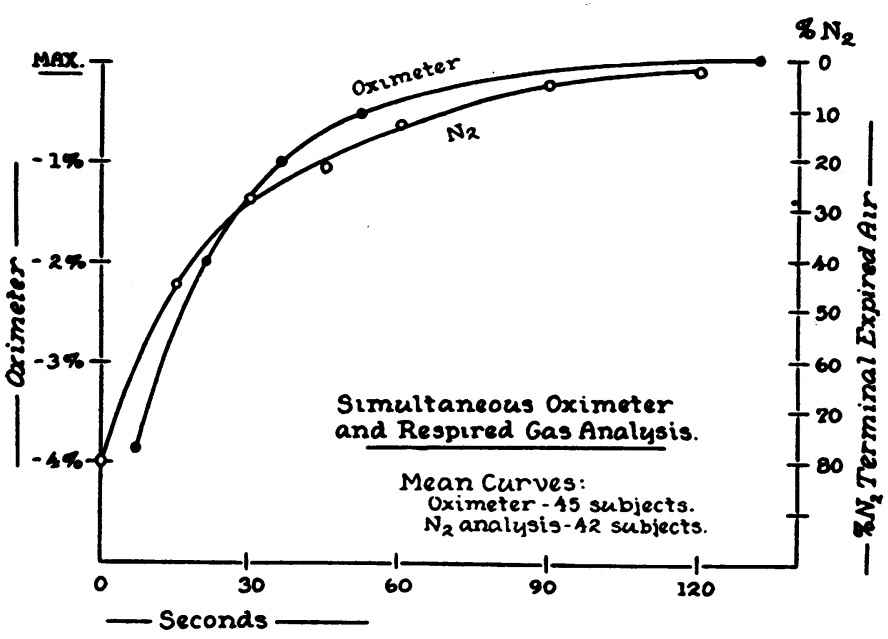

Fig. 2. Simultaneously Determined Rates of Increase of Arterial Oxygen Saturation and Decrease of Concentration of Nitrogen in the Expired Gas During the INHALATION OF $99.6 \%$ OXYGEN

After this delay, the saturation increases rapidly, and then more slowly until a relatively stable plateau has been reached. Minor fluctuations not exceeding $0.5 \%$ may occur about this plateau. They are of two types. One type is irregular and probably instrumental. The other is rhythmic and phasic with respiration, seen both on saturation and ear thickness oximeter readings in some persons; it probably indicates slight variations in blood content of the ear against which the oximeter is not completely compensated. These fluctuations about the plateau create a variability in the time at which a single absolute maximum may be recorded. We have therefore previously (3) arbitrarily recorded the time to absolute maximum minus $0.5 \%$ ( 52 seconds average) rather than to an absolute single maximum (132 seconds average). This is justified by the calculation that there is a $54 \%$ coefficient of variation in the time to absolute single maximum saturation as opposed to the smaller and quite uniform coefficients of variation of $35 \%, 32 \%$ and $30 \%$, respectively, at maximum minus $0.5 \%$, maximum minus $1.0 \%$ and maximum minus $2.0 \%$ levels. The times to maximum minus $0.5 \%$ (average 52 seconds, S. D. 18.6 seconds) or to maximum minus $1.0 \%$ (average 36 seconds, S. D. 11.6 seconds) are more useful in the determination of abnormal delay in reaching full saturation. The mean increase upon inhalation of $100 \% \mathrm{O}_{2}$ was
$3.72 \%$ with a standard deviation of $0.81 \%$ and range from $2.25 \%$ to $5.75 \%$. Whether this signifies that the mean arterial oxygen saturation of normal persons breathing room air is $96.3 \%$ will be discussed later.

2. The rate at which alveolar $\mathrm{pO}_{2}$ rises during inhalation of $\mathrm{O}_{2}$. The decrease in $\mathrm{N}_{2}$ content of lung air, as it was displaced by quiet breathing of $\mathrm{O}_{2}$, is shown in Figure 2 with the simultaneous oximeter readings of 42 subjects. Mean values of the maximal nitrogen content of terminal expired air are plotted at 15 -second intervals. The curve shows that nitrogen content decreases rapidly, i.e., that oxygen content increases rapidly. For example, after the first breath of $\mathrm{O}_{2}$, the mean $\mathrm{N}_{2}$ content of the terminal expired air was found to be $65 \%$. This figure may be converted to approximate oxygen tension by the formula: $\mathrm{pO}_{2}=\left(100-\% \mathrm{~N}_{2}-\% \mathrm{CO}_{2}\right)(\mathrm{B}-47)$. Thus, assuming a content of $5.6 \% \mathrm{CO}_{2}$, we find that the oxygen tension of the terminal expired air had a mean value of $210 \mathrm{~mm}$. Hg. Similarly after 30 seconds the mean $\mathrm{pO}_{2}$ of terminal expired air was $470 \mathrm{~mm}$. $\mathrm{Hg}$. The $\mathrm{pO}_{2}$ of the terminal expired air does not accurately represent the $\mathrm{pO}_{2}$ of "deeper" lung air as shown by the following measurements made upon the same 42 subjects with the nitrogen meter: After breathing room air, two quiet breaths of $\mathrm{O}_{2}$ were taken. Following the second normal expiration, a further forced 
maximal expiration was made. It was found that the maximal $\mathrm{N}_{2}$ content of this "deeper" lung air had a mean value of $3.9 \%$ more than that of the air expelled at the quiet end of the same expiration. Thus the mean $\mathrm{pO}_{2}$ of "deeper" lung air was about $28 \mathrm{~mm}$. less than that of the ordinary terminal expired air. If it be assumed that this difference is due to stratification of gas in the terminal air passages, the $\mathrm{pO}_{2}$ of the deeper lung air would still be considerably in excess of $159 \mathrm{~mm}$. $\mathrm{Hg}(210-28=182 \mathrm{~mm} . \mathrm{Hg})$ at the end of the first breath of $\mathrm{O}_{2}$. However if the difference between the composition of terminal expired air and of "deeper" lung air ${ }^{4}$ be due to regional inequalities in lung ventilation, an explanation might be provided for the slowness of rise in oximeter readings. To test this possibility, further experiments were performed.

3. Effect of hyperventilation upon the rate of increase in saturation. Figure 3 shows the mean

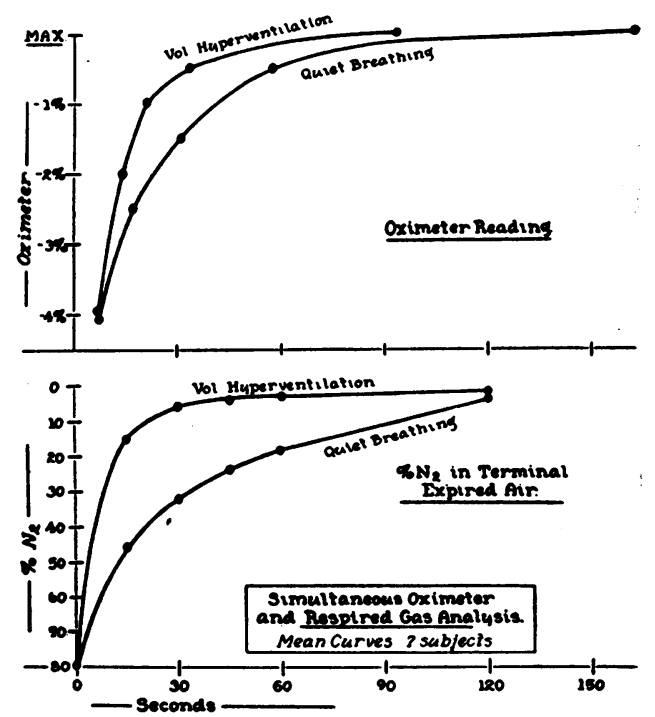

Fig. 3. The Effect of Voluntary Hyperventilation upon the Rate of Change in Arterial Oxygen Saturation and Concentration of Nitrogen in Expired Gas During the In halation of $99.6 \%$ Oxygen

4 No one has ever analyzed the air in immediate contact with the pulmonary capillaries. Instead investigators have analyzed the various portions of lung air as they are expired chronologically during forced expiration. The terminal portion chronologically is not necessarily that air in most intimate contact with normal alveolar lining. We believe that "terminal expired air" and "deeper lung air" are both portions of so-called "alveolar air." oximeter curves of seven subjects by whom $\mathrm{O}_{2}$ inhalation was performed both with quiet breathing and with moderate voluntary hyperventilation for the first $\mathbf{3 0}$ seconds. The sequence of procedures was reversed in alternate subjects. In all cases hyperventilation speeded the rate of saturation increase. With extreme hyperventilation (inhalation of $\mathrm{O}_{2}$ beginning at the maximal expiratory position) the time to maximal saturation decreased further and approached the combined circulatory and instrumental time lag. Thus one might conclude that hypoventilation during quiet breathing is responsible for the delay and that voluntary hyperventilation will reduce it. However, vigorous breathing not only may facilitate ventilation of poorly aerated areas of the lung but also increases the $\mathrm{pO}_{2}$ more rapidly in the well-ventilated areas, as may be inferred from the curves representing $\mathrm{N}_{2}$ content in Figure 3.

Attempts were made to differentiate, if possible, these two factors of increased ventilation and increased $\mathrm{pO}_{2}$ by the following method involving inhalation of $40 \% \mathrm{O}_{2}$. $40 \% \mathrm{O}_{2}$ was chosen since its inhalation should result in an alveolar $\mathrm{pO}_{2}$ at equilibrium well in excess of $159 \mathrm{~mm}$. $\mathrm{Hg}\left(\mathrm{pO}_{2}\right.$ of approximately $240 \mathrm{~mm}$. $\mathrm{Hg}$, assuming a $\mathrm{pCO}_{2}$ of $40 \mathrm{~mm}$. $\mathrm{Hg}$ and an $\mathrm{R}$. Q. of 0.83 ).

Seven subjects breathed $40 \% \mathrm{O}_{2}$ for five minutes. A five-minute period of inhalation should be sufficient to reach equilibrium and overcome any delay due to hypoventilation since maximal saturations are reached in much shorter times in normal subjects. The saturation increased a mean of $2.43 \%$ and then became stable. Then without interruption of respiratory rhythm the subjects breathed $100 \% \mathrm{O}_{2}$. In all cases a further increase in saturation occurred within one minute. The mean increase was $0.89 \%$; the standard error of the mean was 0.091 , giving a $t$ value of 9.9 , which indicates that the increase is a highly significant variation from zero. Ear thickness readings taken before and after the change to $100 \% \mathrm{O}_{2}$ were the same so that it is unlikely that a vascular change caused the alteration. However it is possible that the five-minute period with the lower diffusion pressure resulting from inhalation of $40 \% \mathrm{O}_{2}$ was not so effective in overcoming hypoventilation as was the one-minute period breathing $100 \% \quad \mathrm{O}_{2}$ with a much higher diffusion pressure. Further experiments were done to clarify this point. 
Seven different subjects breathed $40 \% \quad \mathrm{O}_{2}$ for five minutes; saturation increased a mean value of $2.78 \%$ and became stable. The subjects voluntarily hyperventilated for 30 seconds and then resumed quiet breathing of $40 \% \mathrm{O}_{2}$ for two minutes. There was no evidence of a significant change; three increased by $0.5 \%$ but the others showed no change or a decrease of $0.25 \%$. Then the subjects inhaled $100 \% \mathrm{O}_{2}$, still breathing quietly. In all cases, a further oximeter rise occurred, the mean increase being $0.82 \%$.

We have found that the reverse occurs when room air is breathed by a subject who had previously breathed $\mathrm{O}_{2}$. A subject quietly breathed $40 \% \mathrm{O}_{2}$ for five minutes. Saturation increased $3.25 \%$ above the room air value. Voluntary hyperventilation of $40 \% \mathrm{O}_{2}$ for 40 seconds, followed by quiet breathing of $40 \% \quad \mathrm{O}_{2}$ for three minutes, produced no increase in saturation. Then $100 \%$ $\mathrm{O}_{2}$ was breathed for three minutes; saturation increased $1 \%$. $40 \% \mathrm{O}_{2}$ was breathed again for four minutes; saturation decreased $1 \% .100 \% \mathrm{O}_{2}$ was inhaled for four minutes and saturation increased $1.25 \%$. Saturation decreased $1 \%$ upon subsequent inhalation of $40 \% \mathrm{O}_{2}$ and a further $3 \%$ upon breathing room air.

\section{DISCUSSION}

It has been shown that complete oxygen saturation of the arterial blood is reached more slowly than expected after inhalation of $\mathrm{O}_{2}$. This delay (mean, 52 seconds) is considerably in excess of the lags involved in the circulation time from pulmonary to ear capillaries and in the galvanometer. Since it has been shown (11) that the uptake of $\mathrm{O}_{2}$ by $\mathrm{Hb}$ can occur in a fraction of a second, this cannot explain the delay. Since the $\mathrm{pO}_{2}$ of terminal expired air is about $210 \mathrm{~mm}$. $\mathrm{Hg}$ and of "deeper" lung air is about $182 \mathrm{~mm}$. $\mathrm{Hg}$ after one breath of $\mathrm{O}_{2}$, inadequate alveolar $\mathrm{pO}_{2}$ should not be the explanation, unless the customary belief that a $\mathrm{pO}_{2}$ of $159 \mathrm{~mm}$. $\mathrm{Hg}$ will completely saturate the arterial blood is fallacious. Evidence has been presented which leads us to believe that this concept is erroneous and that alveolar and arterial tensions considerably in excess of $159 \mathrm{~mm}$. Hg $\mathrm{pO}_{2}$ must be present.

Certain questions must be considered before this conclusion can be accepted.

First, are there shunts through or around the lungs (other than through hypoventilated alveoli) delivering sufficient venous blood into the arterial circulation that complete arterial saturation could be attained only by drawing upon $\mathrm{O}_{2}$ dissolved by pressures greater than $159 \mathrm{~mm}$. $\mathrm{Hg}$ ? This would prolong the time to full saturation until a sufficient excess of dissolved $\mathrm{O}_{2}$ were available. In such a case, there should be a disparity between alveolar $\mathrm{pO}_{2}$ and arterial $\mathrm{pO}_{2}$. Berggren (12) found this difference to be only $11 \mathrm{~mm} . \mathrm{Hg}$ and Fasciolo and Chiodi (13) estimated it as $35.8 \mathrm{~mm}$. $\mathrm{Hg}$ after some minutes of $\mathrm{O}_{2}$ inhalation. This represents a venous admixture of $0.6-2.0 \%$ of the total blood flow assuming a normal $\mathrm{A}-\mathrm{V}$ difference. However, in our subjects breathing $40 \% \mathrm{O}_{2}$, it may be calculated that there can be enough dissolved $\mathrm{O}_{2}$ to saturate completely a venous admixture of $4 \%$ of the total blood flow, without dropping the $\mathrm{pO}_{2}$ below $160 \mathrm{~mm}$. $\mathrm{Hg}$. Therefore, if a $\mathrm{pO}_{2}$ of $160 \mathrm{~mm}$. $\mathrm{Hg}$ were sufficient to completely saturate hemoglobin, the inhalation of $40 \%$ $\mathrm{O}_{2}$ should saturate arterial blood completely despite the presence of two to six times the amount of venous admixture thought to occur in man. Consequently the additional increase in saturation that occurs on breathing $100 \% \mathrm{O}_{2}$ following $40 \% \mathrm{O}_{2}$ can scarcely be explained solely on the basis of further saturation of venous shunted blood.

A second question is whether the blood in the vasodilated ear represents true arterial blood or whether ear metabolism creates an unsaturation that can be overcome only by very high oxygen tensions. Lilienthal and Riley found no significant difference between the $\mathrm{O}_{2}$ saturation of arterial blood and cutaneous blood obtained from the ear warmed by radiant heat (14). Comroe and Walker (15) found that the average oximeter rise when $\mathrm{O}_{2}$ inhalation followed room air was $3.8 \%$ while the saturation rise determined simultaneously by direct determinations upon arterial blood amounted to only $2.5 \%$. This might mean that the oximeter scale is imperfectly calibrated in the 96-100 range or that the saturation of the ear blood analyzed by the oximeter is $1.3 \%$ less than arterial blood. Even if the latter is true, an initial arterial $\mathrm{pO}_{2}$ of $240 \mathrm{~mm}$. $\mathrm{Hg}$ should provide suffiient excess dissolved $\mathrm{O}_{2}$ to saturate this without reducing final arterial $\mathrm{pO}_{2}$ below $159 \mathrm{~mm}$. $\mathrm{Hg}$. Since the inhalation of $100 \% \mathrm{O}_{2}$ leads to an alveolar $\mathrm{pO}_{2}$ in excess of this by the second breath, 
even the maximal unsaturation credited to ear blood should be overcome very promptly. Thus this factor alone cannot explain the slower rise of $\mathrm{O}_{2}$ saturation to its maximum. This assumes that there is little or no difference between alveolar and arterial $\mathrm{pO}_{2}$ during the period of rapid change in alveolar gas tensions; this remains to be proven experimentally, though preliminary experiments indicate that this assumption is valid.

It appears that no one of the factors of delayed ventilation, venous shunts other than through poorly ventilated alveoli, or ear metabolism will completely explain the slow rise in saturation upon $\mathrm{O}_{2}$ breathing, though each may occur. We believe that a more important factor is the failure of complete saturation of $\mathrm{Hb}$ to occur at an arterial or alveolar $\mathrm{pO}_{2}$ of $160 \mathrm{~mm}$. $\mathrm{Hg}$. The extreme upper end of the oxygen dissociation curve of blood hemoglobin has not been so well defined as other parts of the curve, principally due to the small changes in saturation with large changes in oxygen tension, and to the technical limitations of the methods used. Adair (16) proposed that the hemoglobin molecule, which is probably a fourunit aggregate, takes up $4 \mathrm{O}_{2}$ molecules in successive steps, each reaction involving the addition of one $\mathrm{O}_{2}$ molecule having a different equilibrium constant. Ferry and Green (17) also found that their data on the uptake of $\mathrm{O}_{2}$ by $\mathrm{Hb}$ could be represented by a 4 constant equation, that is, that $\mathrm{Hb}$ appears to behave as though it were a mixture of substances, the reactions of each obeying the general form of the mass law equation. It has been suggested by Dr. F. J. W. Roughton (18) that in the very high saturation range considered here, we are dealing with only the last one of these equilibrium reactions, in which unsaturation is inversely proportional to the $\mathrm{pO}_{2}$. It must follow therefore that, if blood hemoglobin is $97 \%$ or $98 \%$ saturated at an oxygen tension of $100 \mathrm{~mm}$. $\mathrm{Hg}$, and if the same equilibrium constant holds for increasing tension-saturation relationships, $100 \%$ saturation cannot be attained at a $\mathrm{pO}_{2}$ of $160 \mathrm{~mm}$. $\mathrm{Hg}$. Moreover such a relationship would be graphically expressed by a reciprocal curve. If we look at Figures 1 and 3 and visualize increasing $\mathrm{O}_{2}$ tension plotted on the time axis, the oximeter curves (saturation) definitely suggest such a reciprocal relationship. The manner in which saturation decreases when room air is breathed following oxygen inhalation, as shown in Figure 4, supports this view. By comparison with Figure 1 , it is apparent that the fall in saturation follows a much different time course than does the rise. However, when $\mathrm{O}_{2}$ tension is being reduced in the manner shown in Figure 4, saturation should decrease in a course approximately like the observed fall, if following the reciprocal relationship.

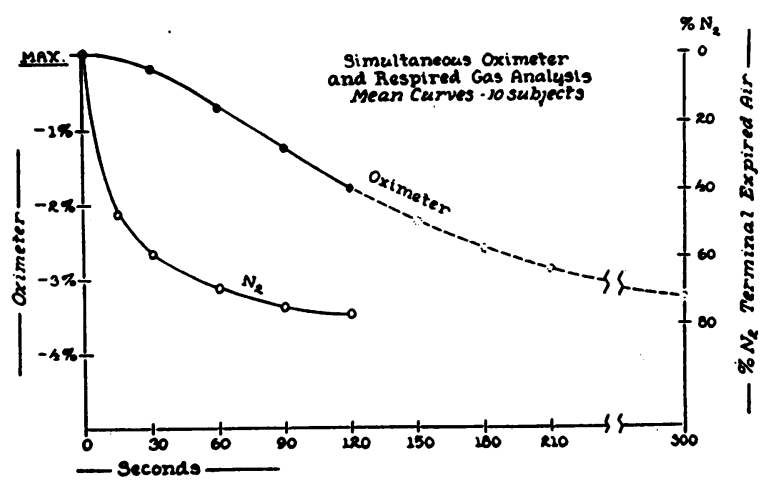

Fig. 4. Simultaneously Recorded Changes in Arterial Oxygen Saturation (Oximeter) and Concentration of Nitrogen In Expired Air During the Change from Inhalation of Oxygen to Room Air

In view of the previously noted multiplicity of variables which affect the final oximeter readings, it is doubtful whether oximeter data obtained in this way, which is in essence a rapidly changing series of equilibrations, should be interpreted more rigidly in an attempt to define the upper end of the oxygen dissociation curve.

A final question which we cannot evaluate' lies in the possibility of gradual reversion to oxyhemoglobin of previously inactive forms of hemoglobin.

The rate of increase in arterial oxygen saturation following the inhalation of oxygen is the end result of various processes such as (1) movement of oxygen to the alveoli, which involves respiratory rate, depth and mixing of gases in the lungs ; (2) diffusion of $\mathrm{O}_{2}$ across the alveolar-capillary membrane into the red cells; (3) conversion of reduced $\mathrm{Hb}$ to $\mathrm{HbO}_{2}$; and (4) transport of $\mathrm{HbO}_{2}$ to the site of measurement. As one or more of these various functions are disturbed by diseases, one might expect the disturbance to be revealed in such a measurement. Figure 5 illustrates curves from a patient with emphysema and from 
another with primary pulmonary arteriolar sclerosis (Ayerza's disease). It is seen that one can measure $(a)$ the delay time (mouth to lung to ear time), (b) the total rise in oximeter reading, and (c) the rate of rise of oxygen saturation. We believe that this test is useful as a simple, innocuous, objective, overall measurement of certain aspects of lung function. It is not an analytical test but is useful as a screening test preliminary to a more complete study of cardiopulmonary function.
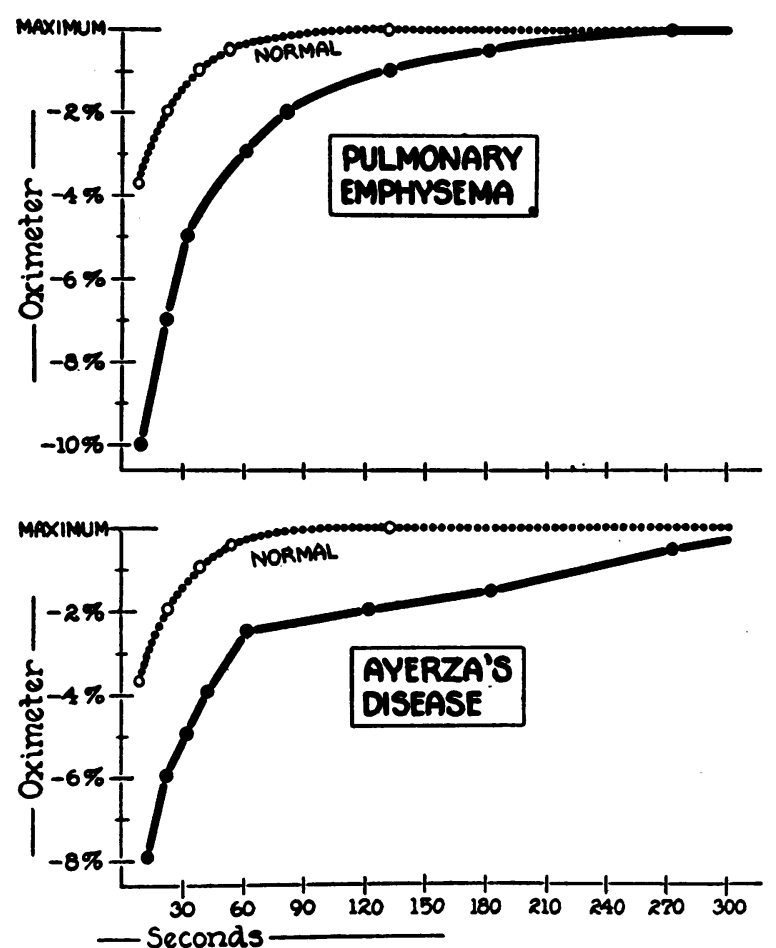

Fig. 5. Rate of Increase of Arterial Oxygen Saturation in a Patient with Pulmonary Emphysema (Upper) and in a Patient with Pulmonary ArteRIOLOSCLEROSIS (LOWER)

\section{SUMMARY}

1. Measurements were made with the oximeter of : $a$. The increase in arterial oxygen saturation which follows quiet and vigorous breathing of $99.6 \%$ oxygen. $b$. The decrease in arterial oxygen saturation which occurs when room air is breathed following a period of oxygen inhalation. $c$. The increase in arterial oxygen saturation which occurs when $99.6 \%$ oxygen is breathed following a period of $40 \% \mathrm{O}_{2}$ inhalation.
2. Continuous measurements of the $\mathrm{N}_{2}$ content of the respired gases were made simultaneously with oximeter recordings.

3. The attainment of maximum arterial saturation following inhalation of $99.6 \%$ oxygen requires a longer time than is readily explainable, if uniform lung ventilation and complete saturation of $\mathrm{Hb}$ at an arterial $\mathrm{pO}_{2}$ of $160 \mathrm{~mm}$. $\mathrm{Hg}$ are assumed. Non-uniformity of the composition of alveolar air was demonstrated; but the magnitude of this factor is not believed to be sufficient to explain the delay in attaining maximum saturation. Neither the shunting of venous blood into the arterial circulation, nor the metabolic reduction of oxyhemoglobin in the ear adequately explains the delay. The occurrence of a small increase in oxygen saturation of the arterial blood at arterial oxygen tensions between 160 and $670 \mathrm{~mm}$. $\mathrm{Hg}$ will explain the experimental results.

4. The usefulness of the oximeter rate as a simple, preliminary screening test for the detection of pulmonary disability is discussed. ${ }^{5}$

\section{BIBLIOGRAPHY}

1. Matthes, K., Queraltó, J. G., and Malikiosis, X., Untersuchungen über den Gasaustausch in der menschlichen Lunge. 5. Mitteilung: Uber das Verhalten der arteriellen Sauerstoffsättigung bei hohen alveolaren Sauerstoff spannungen. Arch. f. exper. Path. u. Pharmakol., 1937, 185, 622.

2. Dirken, M. N. J., Uber die ungleichmassige Zusammensetzung der Alveolärluft. Arch. f. exper. Path. u. Pharmakol., 1937, 187, 462.

3. Fowler, W. S., and Comroe, J. H., Jr., The rate of increase of arterial oxygen saturation following inspiration of $100 \%$ oxygen. Federation Proc, 1947, 6, 104.

4. Van Slyke, D. D., and Stadie, W. C., The determination of gases of blood. J. Biol. Chem., 1921, $49,1$.

5. Henderson, L. J., Blood, a Study in General Physiology. Yale Univ. Press, New Haven, 1928.

6. Millikan, G. A., The oximeter, an instrument for measuring continuously oxygen saturation of arterial blood in man. Rev. Scient. Instruments, 1942, 13, 434.

7. Hemingway, A., and Taylor, C. B., Laboratory tests of oximeter with automatic compensation for vasomotor changes. J. Lab. \& Clin. Med., 1944, 29, 987.

5 The authors wish to express their appreciation to Dr. John Lilly for his advice on the operation of the nitrogen meter and to Dr. Edwin Cornish, Stella Botelho, and Sylvia Himmelfarb for their assistance. 
8. Lilly, J. C., and Hervey, J. P., a. In preparation.

b. Science in World War II. Advances in Military Medicine; The Committee on Medical Research. Little Brown \& Co., Boston, 1948, Vot. 1, p. 314.

9. Lilly, J. C., Studies on the mixing of gases within the respiratory system with a new type nitrogen meter. Federation Proc., 1946, 5, 64.

10. Wexler, J., and Whittenberger, J. L., Objective method for determining circulation time from pulmonary to systemic capillaries by use of oximeter. J. Clin. Invest., 1946, 25, 447.

11. Hartridge, H., and Roughton, F. J. W., The rate of distribution of dissolved gases between the red corpuscle and its fluid environment; preliminary experiments on rate of uptake of oxygen and carbon monoxide by sheep's corpuscles. J. Physiol., 1927, 62, 232.

12. Berggren, S., The oxygen deficit of arterial blood caused by nonventilating parts of the lung. Acta Physiol. Scand., 1942, 4, supp. 11.
13. Fasciolo, J. C., and Chiodi, H., Arterial oxygen pressure during pure oxygen breathing. Am. J. Physiol., 1946, 147, 54.

14. Lilienthal, J. L., Jr., and Riley, R. L., On determination of arterial oxygen saturations from samples of "capillary" blood. J. Clin. Invest., 1944, 23, 904.

15. Comroe, J. H., Jr., and Walker, P., Normal human arterial oxygen saturation determined by equilibration with $100 \% \mathrm{O}_{2}$ in vivo and by the oximeter. Am. J. Physiol.-in press.

16. Adair, G. S., The hemoglobin system; VI. The oxygen dissociation curve of hemoglobin. J. Biol. Chem., 1925, 63, 529.

17. Ferry, R. M., and Green, A. A.; Studies in the chemistry of hemoglobin. III. The equilibrium between oxygen and hemoglobin and its relation to changing hydrogen ion activity. J. Biol. Chem., 1929, 81, 175.

18. Roughton, F. •J. W., Personal communication. 